\title{
Diagnostic criteria for the determination of clinically significant internal carotid artery stenosis using duplex ultrasound
}

\author{
Karel Gorican ${ }^{\mathrm{a}}$, Miroslav Chochola ${ }^{\mathrm{b}}$, Miroslav Kocik $^{\mathrm{a}}$, Ales Zak ${ }^{\mathrm{a}}$
}

\begin{abstract}
Background. Carotid endarterectomy is beneficial in symptomatic patients with $\geq 70 \%$ stenosis at the bifurcation of the internal carotid artery. The fact that the duplex ultrasound is widely used, inexpensive and non-invasive for examination of the carotid arteries underlines the importance of high accuracy of this method for grading internal artery stenosis. Patients and Methods. Duplex scans and arteriograms of carotid arteries of 142 patients were reviewed. Peak and end-diastolic velocities of the common and internal carotid arteries were recorded, and the percent stenosis of the internal carotid artery was determined by arteriogram. Receiver-operator characteristic curves of sensitivity, specificity, positive and negative predictive values and accuracy were determined.

Results. The recommended criteria for the detection of $\geq 70 \%$ stenosis of the internal carotid artery were: peak systolic velocity in the internal carotid artery $\geq 215 \mathrm{~cm} / \mathrm{s}$, end-diastolic velocity in the internal carotid artery $\geq 65 \mathrm{~cm} / \mathrm{s}$, ratio of peak systolic velocities in the internal and common carotid arteries $\geq 2.7$ and ratio of the end-diastolic velocities of the internal and common carotid arteries $\geq 3.7$.
\end{abstract}

Conclusion. These criteria allow for reliable determination of internal carotid artery stenosis $\geq 70 \%$ by duplex ultrasound.

Key words: carotid stenosis, diagnosis, duplex ultrasound, extracranial occlusive disease

Received: February 23, 2019; Revised: May 14, 2019; Accepted: June 3, 2019; Available online: June 17, 2019

https://doi.org/10.5507/bp.2019.029

(c) 2020 The Authors; https://creativecommons.org/licenses/by/4.0/

${ }^{a} 4$ th Department of Internal Medicine, First Faculty of Medicine, Charles University in Prague and General Teaching Hospital in Prague, Prague, Czech Republic

'2nd Department of Internal Medicine, First Faculty of Medicine, Charles University in Prague and General Teaching Hospital in Prague, Prague, Czech Republic

Corresponding author: Karel Gorican, e-mail:kgori@vfn.cz

\section{INTRODUCTION}

In the Czech Republic, stroke is a serious national health problem. It is, after ischaemic heart disease and cancer, the third most common cause of death. In men it accounts for $16 \%$, and in women $18.4 \%$, of all deaths due to circulatory diseases. Statistical data give the number of deaths due to cerebrovascular disease in 2017 as 8504 persons, $57 \%$ of these were women ${ }^{1}$.

Internal carotid artery stenosis is an important cause of ischemic stroke ${ }^{2}$. The results of large intervention studies have shown that prompt surgical treatment reduces significantly stroke mortality and morbidity in patients with a $\geq 70 \%$ symptomatic stenosis of the internal carotid artery $^{3}$, and there is also some benefit in patients with $50-69 \%$ stenosis ${ }^{4}$. The criteria for the determination of the severity of internal carotid artery stenosis using duplex ultrasound published so far are not directly applicable in a different ultrasound laboratory ${ }^{5}$. We have decided to set our own diagnostic criteria for the determination of internal carotid artery stenosis $\geq 70 \%$ using duplex ultrasound.

\section{MATERIAL AND METHODS}

We used duplex ultrasound over a period of 34 months to examine 142 patients who also had an angiography of their carotid arteries performed within 4 days to four weeks of the ultrasound. The patient file included 98 men and 44 women, age 36 to 83 years, average age 64.2 years. From this group of 284 carotid arteries examined angiographically and by ultrasound, all patients with an occluded common or internal carotid artery were excluded (27 arteries $=9.5 \%)$ as well as all patients with an occluded or more than $50 \%$ stenosis of the brachiocephalic trunc, or with a more than $50 \%$ stenosis of the common carotid artery $(15$ arteries $=5.3 \%)$, or patients with a bilateral internal carotid artery stenosis of $60 \%$ or more $(40$ arteries $=14.1 \%)$. Angiography that did not reach an excellent technical quality for exact measurement were not used for final measurement ( 49 arteries $=17.3 \%$ ). The final set used for further evaluation thus included 153 $(=53.9 \%)$ carotid arteries.

A Sonos 2500 color duplex system with a $7.5 \mathrm{MHz}$ linear vascular transducer was used for the ultrasound examination. The whole cervical carotid arteries were scanned using B mode and color flow mapping, velocity measurement was performed at location where stenosis 
was suspected. Peak systolic and end diastolic velocities at $60^{\circ}$ incidence angle were measured in the common carotid artery $1 \mathrm{~cm}$ below of the bulb, and then in the proximal internal and external carotid artery.

Intraarterial digital subtraction angiography was used for the angiographic examination. The imaging of the arteries dividing from the aortic arch was followed by selective angiography of the bifurcation of the carotid arteries in at least two projections. The diameter of the narrowest part and the distal part of the internal carotid artery where it regained a stable diameter were measured under magnification. The measured values were then used to calculate the stenosis in \% - NASCET method ${ }^{6}$.

The data acquired by duplex ultrasound examination were used to calculate sensitivity, specificity, positive and negative predictive values and accuracy for the group of patients with a $\geq 70 \%$ stenosis of the internal carotid artery demonstrated on angiography.
All duplex ultrasound examinations were performed by single vascular sonographer (Karel Gorican), all angiographic examinations were performed and read by interventional radiologist (Miroslav Chochola).

\section{RESULTS}

A $\geq 50 \%$ stenosis of the internal carotid artery was present in 76 cases ( $49.7 \%$ ), and a $\geq 70 \%$ stenosis was present 63 cases (41.2\%) of angiographic findings. Diagrams 2 to 5 show the courses of sensitivity, specificity, positive and negative predictive values of monitored parameters: peak systolic velocity, end diastolic velocity in internal and common carotid arteries and the ratio of peak systolic and end diastolic velocities in the internal and common carotid arteries in patients with a $\geq 70 \%$ stenosis of the internal carotid artery in the angiographic reading.

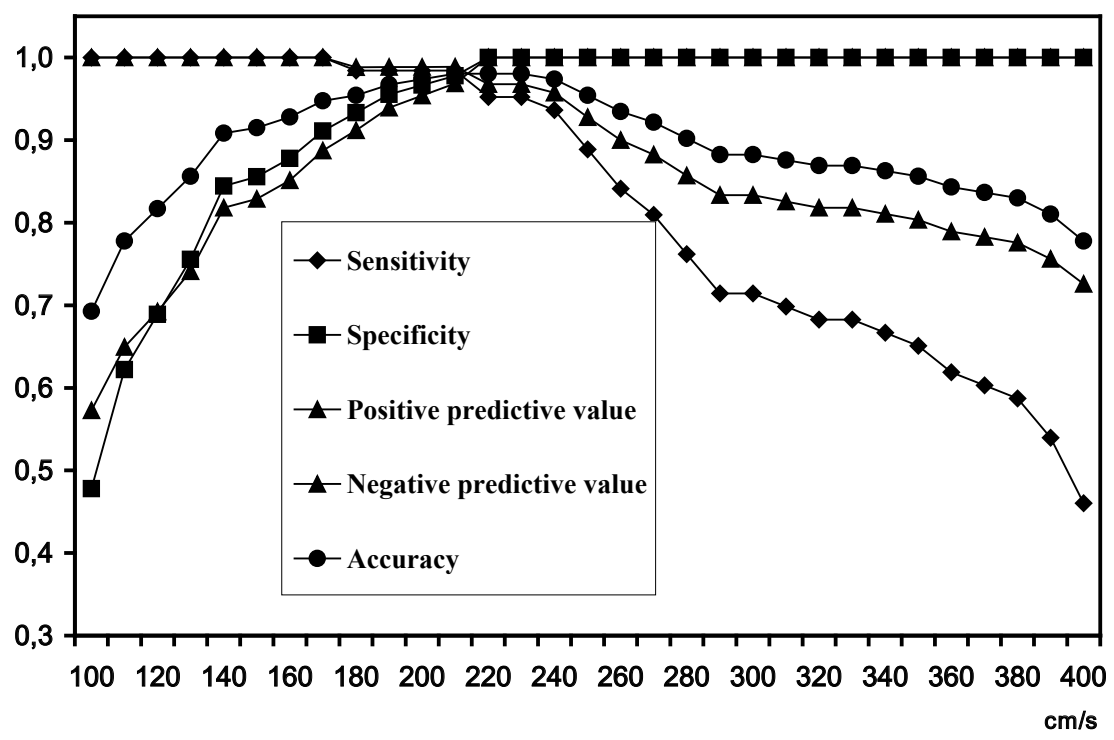

Fig. 1. Peak systolic velocity in the internal carotid artery.

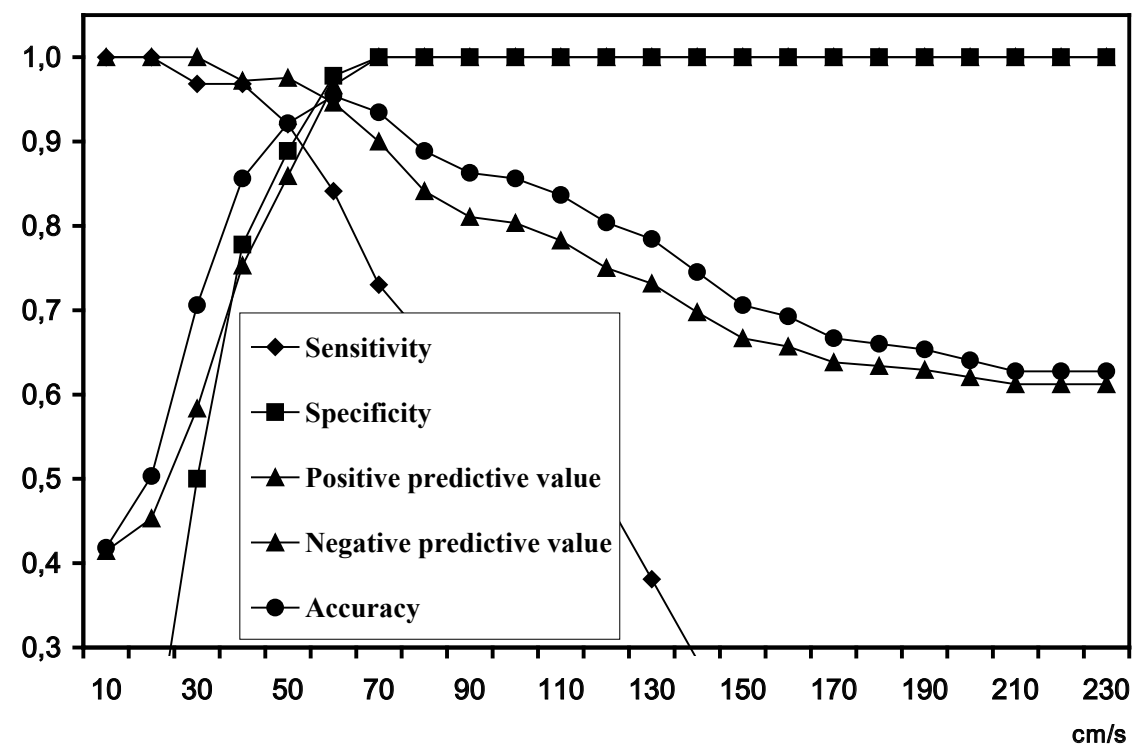

Fig. 2. Enddiastolic velocity in the internal carotid artery. 


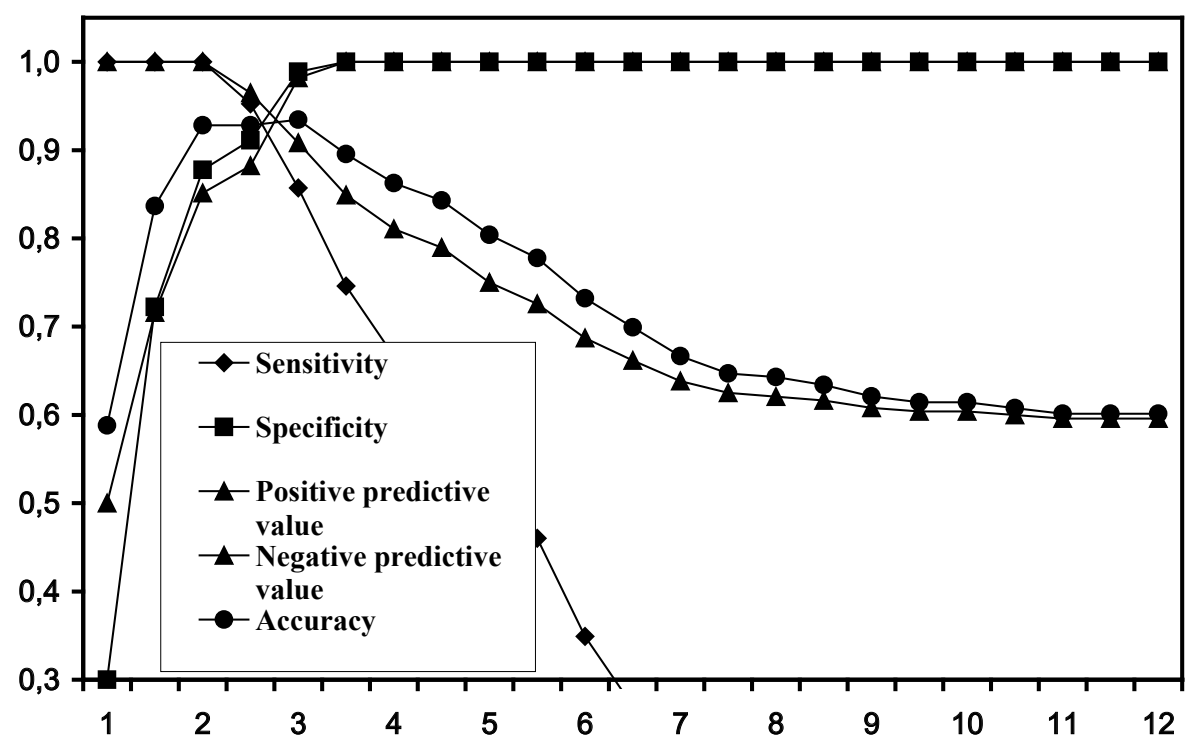

Fig. 3. Ratio of peak systolic velocities in the internal and common carotid artery.

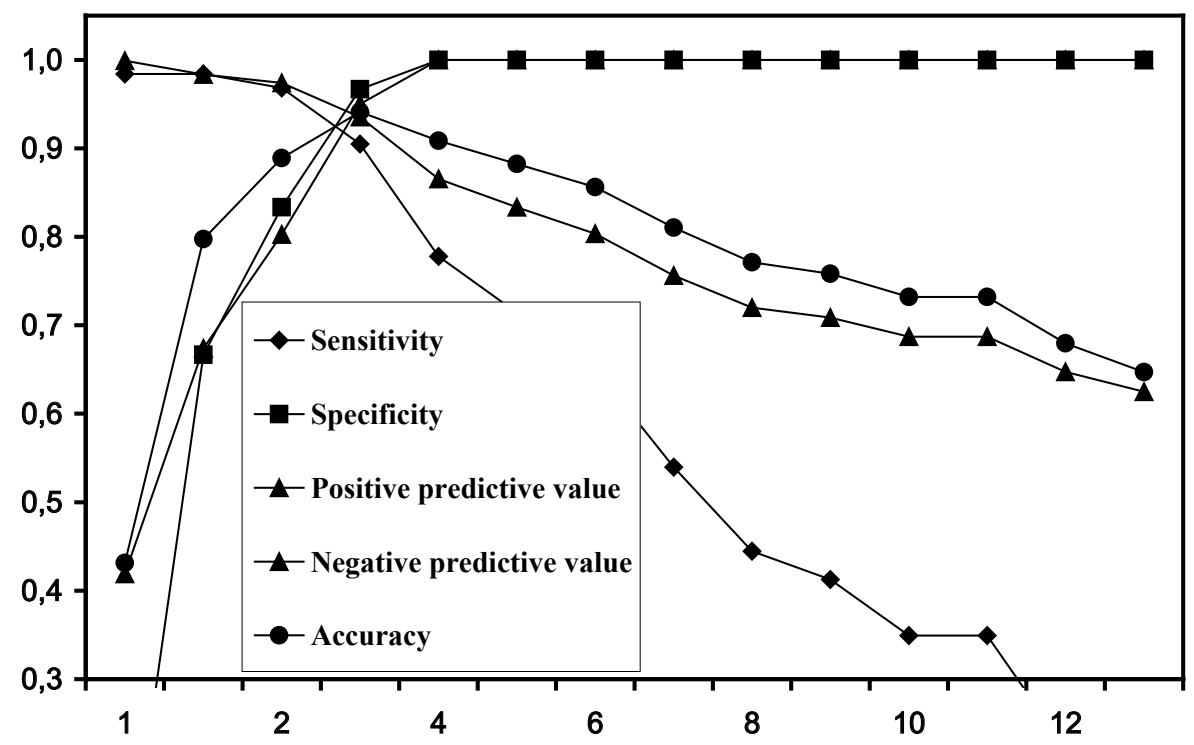

Fig. 4. Ratio of enddiastolic velocities in the internal and common carotid arteries.

For the peak systolic velocity at the division of the internal carotid artery, the highest accuracy rate during the determination $\geq 70 \%$ stenosis was $\geq 215 \mathrm{~cm} / \mathrm{s}$. (Fig. 1). In higher velocities, a drop in sensitivity and negative predictive value and simultaneous small enhancement of specificity and positive predictive value were observed.

For end diastolic velocity in the internal carotid artery, the highest accuracy rate during the determination of $\geq 70 \%$ stenosis was $\geq 65 \mathrm{~cm} / \mathrm{s}$. At higher velocities a rapid decline of sensitivity, negative predictive value and accuracy, and simultaneous slight increase of specificity were observed (Fig. 2).

During the evaluation of the ratio of peak systolic velocities in the internal and common carotid artery for the determination of $\geq 70 \%$ stenosis, the highest accuracy was observed at the value of $\geq 2.7$. Higher values of this ratio are accompanied by a sharp drop in sensitivity and negative predictive value, and simultaneous increase of specificity a positive predictive value (Fig. 3).

During the evaluation of the ratio of end diastolic velocities in the internal and common carotid arteries for the determination of $\geq 70 \%$ stenosis, the highest accuracy was observed at the value of $\geq 3.7$. A further increase of this ratio leads to a rapid decrease in sensitivity a negative predictive value, and simultaneous rise of specificity and positive predictive value (Fig. 4). Table 1. and 2. contain the proposed diagnostic criteria.

\section{DISCUSSION}

Extracranial internal carotid artery atherosclerosis is an important cause of large-vessel stroke ${ }^{7}$. The most frequently affected site is the bifurcation of the internal 
Table 1. Suggested velocity criteria for determination of $\geq 70 \%$ stenosis.

\begin{tabular}{lccccc}
\hline Criterion: & $\begin{array}{c}\text { Sensitivity } \\
(\%)\end{array}$ & $\begin{array}{c}\text { Specificity } \\
(\%)\end{array}$ & $\begin{array}{c}\text { PPV } \\
(\%)\end{array}$ & $\begin{array}{c}\text { NPV } \\
(\%)\end{array}$ & $\begin{array}{c}\text { Accuracy } \\
(\%)\end{array}$ \\
\hline V MAX ICA $\geq 215 \mathrm{~cm} / \mathrm{s}$ & 98 & 98 & 98 & 98 & 98 \\
EDV ICA $\geq 65 \mathrm{~cm} / \mathrm{s}$ & 89 & 98 & 98 & 93 & 95 \\
V MAX ICA/V MAX CCA $>2.7$ & 92 & 93 & 91 & 94 & 93 \\
EDV ICA/EDV CCA $>3.7$ & 86 & 98 & 96 & 91 & 93 \\
\hline
\end{tabular}

PSV = peak systolic velocity, EDV = end-diastolic velocity, ICA = internal carotid artery, CCA = common carotid artery, PPV = positive predictive value, $\mathrm{NPV}=$ negative predictive value.

Table 2. Combined velocity criteria for determination of $\geq 70 \%$ stenosis.

\begin{tabular}{lcccccc}
\hline Criterion & $\begin{array}{c}\text { Sensitivity } \\
(\%)\end{array}$ & $\begin{array}{c}\text { Specificity } \\
(\%)\end{array}$ & $\begin{array}{c}\text { PPV } \\
(\%)\end{array}$ & $\begin{array}{c}\text { NPV } \\
(\%)\end{array}$ & $\begin{array}{c}\text { Accuracy } \\
(\%)\end{array}$ & $\begin{array}{c}\mathrm{n}^{*} \\
(\%)\end{array}$ \\
\hline PSV ICA + EDV ICA & 97 & 99 & 98 & 97 & 98 & $56(89)$ \\
PSV ICA + PSV ICA/PSV CCA & 98 & 99 & 98 & 99 & 98 & $56(89)$ \\
PSV ICA + EDV ICA/EDV CCA & 98 & 100 & 100 & 99 & 99 & $59(94)$ \\
EDV ICA + PSV ICA/PSV CCA & 98 & 98 & 98 & 99 & 98 & $52(83)$ \\
EDV ICA + EDV ICA/EDV CCA & 96 & 99 & 98 & 97 & 98 & $54(86)$ \\
PSV ICA/PSV CCA + EDV ICA/EDV CCA & 97 & 99 & 98 & 98 & 98 & $56(89)$ \\
\hline
\end{tabular}

$\mathrm{PSV}=$ peak systolic velocity, $\mathrm{EDV}=$ end-diastolic velocity, ICA = internal carotid artery, $\mathrm{CCA}=$ common carotid artery, $\mathrm{PPV}=$ positive predictive value, $\mathrm{NPV}=$ negative predictive value. ${ }^{*} \mathrm{n}$ (and percentage) of patients who met the combined criteria of the total of 63 patients with $\geq 70 \%$ stenosis.

Table 3. Published Duplex velocity criteria for grading of $70 \%$ internal carotid artery stenosis.

\begin{tabular}{|c|c|c|c|c|c|c|}
\hline Author, year & Machine & $\mathrm{V} \max$ ICA & $\mathrm{V} \min \mathrm{ICA}$ & $\mathrm{V} \max$ ICA/CCA & $\mathrm{V}$ min ICA/CCA & Ref. \\
\hline Robinson, 1988 & Acuson & $>225$ & $>75$ & $>3$ & & 19 \\
\hline Hunik, 1993 & Acuson & $>230$ & & & & 6 \\
\hline Moneta, 1993 & Different & $>325$ & $>110$ & & & 6 \\
\hline Faught, 1994 & Different & $>130$ and & $>110$ & & & 20 \\
\hline Neale, 1994 & Acuson & $>270$ and & $>110$ & & & 6 \\
\hline Eliasziw, 1995 & Different & $250-375$ & & $3-4.5$ & & 21 \\
\hline Carpenter, 1996 & HP Sonos & $>210$ & $>70$ & $>3$ & $>3.3$ & 6 \\
\hline Nicolaides,1996 & Different & $>250$ & & $>4$ & $>15$ & 22 \\
\hline Hood, 1996 & QAD2000 & $>130$ and & $>110$ & & & 23 \\
\hline Chen, 1998 & Acuson & $>125$ and & $>135$ & & & 24 \\
\hline AbuRahma,1998 & ATL & $>150$ and & $>90$ & & & 6 \\
\hline Huston, 2000 & Acuson & $>230$ & $>70$ & $>3.2$ & & 6 \\
\hline
\end{tabular}

$\mathrm{Vmax}=$ peak systolic velocity, $\mathrm{V} \min =$ enddiastolic velocity in $\mathrm{cm} / \mathrm{s}$.

carotid artery, the involvement is bilaterally symetric. Two in three patients with a pathological finding on cerebral angiography have simultaneous involvement of multiple vessels ${ }^{8}$.

The first surgical treatment - plastic surgery - of this disease was performed in 1953 by DeBakey'; the first endarterectomy of a stenosis at the bifurcation of the internal carotid artery performed by Eascott in 1954 (ref. ${ }^{10}$ ). The number of such interventions increased rapidly in the following decades. Frequent perioperative complications and effort to find out which patients will profit from such treatment led to the establishment of a number of clinical studies. The first of these did not demonstrate any favorable impact of surgical treatment because of the large number of complications ${ }^{11}$. It was not until the results of large interventional trials were published in the early 1990s when it became evident that surgical treat- ment - unlike treatment by medication alone - leads to a significant reduction of the number of cerebral vascular accidents in symptomatic patients with internal carotid artery $\geq 70 \%$ stenosis defined on angiography ${ }^{12}$. In the mentioned studies, patients were indicated for endarterectomy on the basis of angiografic findings. The results from the asymptomatic carotid trial were similar for asymptomatic patients ${ }^{13}$. Since duplex ultrasound is the most often used method of examining carotid arteries, these conclusions imply its large importance also for the accurate evaluation of the severity of internal carotid artery stenosis.

The evaluation of the severity of carotid artery stenosis on ultrasound examination is based on the evaluation of the ultrasound tomogram and on doppler examination. The evaluation of less significant stenosis is performed in almost all patients by measurement of the diameter or area on the ultrasound tomogram. The evaluation of 
significant stenosis is usually carried out on the basis of doppler examination.

Comparison of our results with published data (Table 3) shows that the former are close to those measured by Carpenter 1996 (ref. $^{6}$ ).

Our data, however, diverge from those published by other authors, sometimes significantly. There are several explanations. First, it must be pointed out that the velocity measurement is investigator dependent and the results are influenced by individual deviations in methodology and personal experience. The detection of sites of peak systolic velocity may not be simple and fast in all patients. Not taking this fact into account may lead to incorrect results or to a situation when the patient manifests a different stenosis on the basis of systolic criteria than on the basis of end diastolic velocities. This phenomenon evokes the question of which of the provided parameters is "better" for the evaluation of the severity of the stenosis. There is no brief answer and the fact that more parameters are used to evaluate stenosis indicates that none of them is optimal on its own. If velocity values do not allow a definite inclusion of a patient into a defined category, the recommendation is to repeat carefully the whole examination. Literature usually gives peak systolic velocity in the stenosis as the most reliable of these parameters ${ }^{14}$. The prerequisite, however, is the achievement of a signal of adequate quality from the site of the real velocity peak. An important reason for the observed differences may be the different equipment used. The comparison of measurements of constant velocities on six modern duplex systems demonstrated ranging of the results from -4 to $+47 \%$, until today these findings were not ruled out ${ }^{15}$.

It is also necessary to take into account that systolic velocities in very tight stenoses may be actually lower due to decrease of blood flow volume. Another explanation for low systolic velocities in significant stenosis is hypoperfusion of the carotid artery caused, for instance, by a significant stenosis or occlusion located more distally. Another cause for low systolic velocities is low cardiac output. In such cases the grading of the stenosis severity is based on pathological values of the systolic and end diastolic velocities ratios. Velocity measurement performed in dilated segments of arteries leads to lower velocities.

Hyperperfusion of carotid arteries may be global or unilateral. Bilateral hyperperfusion may be found e.g. in some types of arteriovenous malformations or hyperthyreoidism. Unilateral hyperperfusion is found in some types of arteriovenous malformations and typically in patients with counter-lateral significant stenosis or occlusion. Not taken this finding into consideration may lead to the overestimation of the severity of the stenosis. The end diastolic velocity is influenced by the actual heart rate or arrythmias. This might explain the lower predictive value during the demonstration of the stenosis (Table 1).

Severe aortic stenosis or regurgitation and hypertrophic cardiomyopathy my significantly change the doppler waveforms ${ }^{16}$.

The experience acquired during the processing of our group of patients leads us to the opinion that an important factor in the determination of diagnostic criteria is the appropriate selection of patients for the basic cohort used for further analysis. We believe, that we should not use single criteria based on the processing the data of all examined patients to evaluate the findings of patients with significant bilateral involvement of the bifurcation of carotid arteries (i.e. unilateral carotid artery occlusion and stenosis of the other artery, or bilateral significant internal carotid artery stenosis). The data of the whole patient file include a mixture of at least three different groups of patients - patients without stenosis, patients with unilateral stenosis or occlusion, patients with significant bilateral stenosis or occlusion. In the case of patients belonging to the last-mentioned group the pressure gradient, and thus also velocity, in the stenosis are significantly affected by a counter-lateral patency defect. That is why we have included for the purposes of further processing only those patients in our cohort who had not a simultaneous occlusion on one side and stenosis of over $60 \%$ on the other and patients with significant bilateral stenosis. This approach is new and criteria defined in this manner are appropriately applicable only to patients who meet the above-mentioned requirements - which has been most of them in this case. Patients with a bilateral significant carotid artery stenosis or occlusion should be evaluated individually, because of the hyperperfusion in the patent artery leading to an over-estimation of the significance of the stenosis.

A useful ancillary method for the detection of significant stenosis at the bifurcation of the internal carotid artery is the examination of flow in the ophthalmic artery or its branches and transcranial doppler examination ${ }^{17}$. In a number of cases, duplex ultrasound does not allow the direct imaging of the proximal sections of the carotid arteries and branches of the aortic arch. It is evident from a comparison of angiographic and ultrasound findings that duplex ultrasound will document reliably proximally located significant stenosis and occlusions ${ }^{18}$. Similarly, on the basis of doppler velocity measurement it is possible to detect more distally located significant stenosis or occlusion of the internal carotid artery on duplex ultrasound.

In a small number of patients, the examined site is concealed in the shadow of calcification and does not allow either of the methods of examination. It is then necessary to try to image the target area using more atypical views. Doppler examination of more proximally and distally located segments of the vessel may, in such circumstances, provide valuable information.

\section{CONCLUSION}

The main reason for the determination of diagnostic criteria is that they allow the reliable selection of patients for endarterectomy, other type of intervention or angiographic examination. The established velocity criteria involving defined sensitivity, specificity and other parameters, make it possible to determine patients with a $70 \%$ or narrower stenosis at the origin of the internal carotid artery.

In view of what has been said above, and also of the 
fact that a number of works presenting these criteria use different ultrasound systems, the criteria set in this manner are not widely applicable and cannot be used directly by other ultrasound laboratories. It is recommended that every ultrasound laboratory indicating patients for carotid artery intervention should test the published criteria on a sufficient number of patients. Continuous checks of the quality of duplex ultrasound findings by comparing them with the ultrasound findings is necessary even after the determination of the diagnostic criteria ${ }^{5}$. This is the only way ensuring the greatest possible reliability for discrimination of significant stenosis - which is one of the risk factors for stroke.

Acknowledgement: This work has been supported by institutional support RVO VFN64165 from the Czech Ministry of Health and PROGRES-Q25/LF1/2 from the Czech Ministry of Education.

Author contributions: All authors contributed equally to preparing the manuscript.

Conflict of interest statement: The authors state that there are no conflicts of interest regarding the publication of this article.

\section{REFERENCES}

1. Czech health statistics 2017. Prague, ÚZIS Czech Republic, 2018, www.uzis.cz. Accessed on 5.2.2019.

2. Förster A, Gass A, Kern Rolf, Wolf ME, Ottomeyer C, Zohsle K, Hennerici M, Szabo K. Gender differences in Acute Ischemic Stroke. Etiology, Stroke Patterns and Response to Thrombolysis. Stroke 2009;40(7):2428-32.

3. Rothwell PM, Eliasziw M, Gutnikov SA, Fox AJ, Taylor DW, Mayberg MR, Warlow CP, Barnett HJ, Carotid Endarterectomy Trialists' Collaboration. Analysis of pooled data from the randomized controlled trials of endarterectomy for symptomatic carotid stenosis. Lancet 2003;361(9352):107-16.

4. Aboyans V, Ricco JB, Bartelink MEL, Björck M, Brodmann M, Cohnert T, Collet JP, Czerny M, De Carlo M, Debus S, Espinola-Klein C, Kahan T, Kownator S, Mazzolai L, Naylor AR, Roffi M, Röther J, Sprynger M, Tendera M, Tepe G, Venermo M, Vlachopoulos C, Desormais I; ESC Scientific Document Group. 2017 ESC Guidelines on the Diagnosis and Treatment of Peripheral Arterial Diseases, in collaboration with the European Society for Vascular Surgery (ESVS): Document covering atherosclerotic disease of extracranial carotid and vertebral, mesenteric, renal, upper and lower extremity arteries Endorsed by: the European Stroke Organization (ESO)The Task Force for the Diagnosis and Treatment of Peripheral Arterial Diseases of the European Society of Cardiology (ESC) and of the European Society for Vascular Surgery (ESVS). Eur Heart J 2018;39(9):763-816.

5. Grant EG, Benson CB, Moneta GL, Alexandrov AV, Baker JD, Bluth EI, Carroll BA, Eliasziw M, Gocke J, Hertzberg BS, Katanick S, Needleman L, Pellerito J, Polak JF, Rholl KS, Wooster DL, Zierler RE. Society of Radiologists in Ultrasound Consensus Conference on Ultrasound Doppler Diagnosis of Carotid Stenosis. Radiology 2003;229(2):340-6.

6. Mitchell EL, Moneta GL. In: Zwiebel WJ, Pellerito JS. Introduction to vascular ultrasonography. 5 ed. Philadephia: Elsevier Saunders 2005; 178-182.
7. Flaherty ML, Kissela B, Khoury JC, Alwell K, Moomaw CJ, Woo D, Khatri P, Ferioli S, Adeoye O, Broderick JP, Kleindorfer D. Carotid Artery Stenosis as a Cause of Stroke. Neuroepidemiology 2013;40(1):36-41.

8. Hass WK, Fields WS, North WR, Kircheff II, Chase NE, Bauer RB. Joint Study of extracranial arterial occlusion II: Arteriography, techniques, sites and complications. JAMA 1968;203(11):961-8.

9. DeBakey ME. Successful Carotid Endarterectomy for Cerebrovascular Insufficiency. Nineteen-year follow-up. JAMA 1975;233(10):1083-5.

10. Eastcott HH, Pickering GW, Rob CG. Reconstruction of internal carotid artery in a patient with intermittent attacks of hemiplegia. Lancet 1954;267(6846):994-6.

11. Fields WS, Maslenikov V, Meyer JS, Hass WK, Remington RD, Macdonald M. Joint study of extracranial arterial occlusion: V. Progress of prognosis following surgery or nonsurgical treatment for transient cerebral ischemic attacks and cervical carotid artery lesions. JAMA 1970;211(12):1993-2003.

12. North American Symptomatic Carotid Endarterectomy Trial Collaborators, Barnett HJM, Taylor DW, Haynes RB, Sackett DL, Peerless SJ, Ferguson GG, Fox AJ, Rankin RN, Hachinski VC, Wiebers DO, Eliasziw M. Benefitial Effect of Carotid Endarterectomy in Symptomatic Patients with High-Grade Carotid Stenosis. N Engl J Med 1991;325(7):445-53.

13. Endarterectomy for asymptomatic carotid artery stenosis. Executive Committee for the Asymptomatic Carotid Atherosclerosis Study. No authors listed. JAMA 1995;273(18):1421-8.

14. Gaitini D, Soudack M. Diagnosing Carotid Stenosis by Doppler Sonography. State of the Art. J Ultrasound Med 2005;24(18):1127-36.

15. Hoskins PR. Accuracy of maximum velocity estimates made using doppler ultrasound systems. Brit J Radiol 1996;69(818):172-7.

16. Madhwal S, Yesenko S, Kim ESH, Park M, Begelman SM, Gornik HL. Manifestations of Cardiac Disease in Carotid Duplex Ultrasound Examination. JACC: Cardiovasc Img 2014;7(2):200-3.

17. AbuRahma AF, Bergan JJ. Eds. Noninvasive vascular diagnosis. London, Springer Verlag 2007.

18. Gorican K, Chochola M, Bartunek P. Value of Duplex Ultrasound examination in the Detection of the Proximal Aortic Arch Vessels Lesions. Proceedings of the 13st Congress of the European Chapter of the International Union of Angiology, Rhodes, 26-30 May 1999, 95.

19. Robinson ML, Sacks D, Perlmutter GS, Marinelli DL. Diagnostic criteria for carotid duplex sonography. AJR Am J Roentgenol 1988;151(5):1045-9.

20. Faught WE, Mattos MA, van Bemmelen PS, Hodgson KJ, Barkmeier LD, Ramsey DE, Sumner DS. Color-flow duplex scanning of carotid arteries: New velocity criteria based on receiver operator characteristic analysis for treshold stenoses used in the symptomatic and asymptomatic carotid trials. J Vasc Surg 1994;19(5):818-28.

21. Eliasziw M, Rankin RN, Fox AJ, Haynes RB, Barnett HJ. Accuracy and prognostic consequences of ultrasonography in identifying severe carotid artery stenosis. North American Symptomatic Carotid Endarterectomy Trial (NASCET) Group. Stroke 1995;26(10):1747-52.

22. Nicolaides AN, Shifrin EG, Bradbury A, Dhanjil S, Griffin M, Belcaro G, Williams M. Angiographic and Duplex Grading of Internal Carotid Stenosis: Can we Overcome the Confusion? J Endovasc Surg 1996;3(2):158-65.

23. Hood DB, Mattos MA, Mansour A, Ramsey DE, Hodgson KJ, Barkmeier LD, Sumner DS. Prospective evaluation of new duplex criteria to identify $70 \%$ internal carotid artery stenosis. J Vasc Surg 1996;23(2):254-61.

24. Chen JC, Salvian AJ, Taylor DC, Teal PA, Marotta TR, Hsiang YN. Predictive ability of duplex ultrasound for internal carotid artery stenosis of 70\%-99\%: A comparative study. Ann Vasc Surg 1998;12(3):244-7. 